\title{
Research on the Construction Way of College Network Teaching Mode Based on MOOC
}

\author{
Boju Feng, Hongling Zhang \\ Jilin University, School of Continuing Education, Changchun, Jilin, China, 130021
}

Keywords: Construction Way; College Network Teaching Mode; MOOC

\begin{abstract}
With the development of Internet technology, MOOC emerged. As the main position of MOOCs, colleges and universities are undergoing an "Internet+" transformation in the field of higher education. MOOC is not subject to time and space constraints, but teaching resources sharing and other advantages for college students to obtain knowledge with a lot of convenience, but its own limitations are also more obvious, easily overlooking individual differences in students, and teachers and students cannot communicate in real time, which directly affect the quality of college teaching. Therefore, it should be combined with the actual situation of college teaching, college students' cognitive characteristics and practical ability, to build a network teaching model based on MOOC, to achieve the organic integration of MOOC and traditional teaching, in order to stimulate the vitality of classroom teaching and improve the quality of teaching.
\end{abstract}

\section{Introduction}

MOOCs (Some Massive Open Online Courses) are large-scale open courses that are published on the Internet by individuals or organizations that share the spirit of collaboration and are willing to enhance knowledge dissemination. They are a means of using modern technology to implement teaching [1]. Different from traditional teaching, MOOC has shown great advantages in cultivating students' autonomous learning ability, innovation ability, information integration ability, and so on, prompting colleges and universities to continuously reform their teaching concepts, teaching methods, and teaching evaluation. Under such circumstances, how to construct a university-based teaching model based on MOOC has become an urgent problem to be solved.

\section{MOOC Teaching Mode}

The full English name of MOOC is translated as "a large-scale open online course," or "moo." The main features of MOC include learners who reach a scale of tens of thousands of people at a time. All those who want to learn can learn which embodies the concept of "creation and sharing". Online learning is not restricted by time and space. It is a new way of organizing knowledge and learning. The essence of MUC is to maximize the learning and sharing of the best course resources of elite schools by opening up high-quality online curriculum resources globally.

MOOC provides a learner-centered online teaching model with a complete curriculum structure including curriculum objectives, course organizers, topics, time schedules, and assignments. In the MOOC teaching model, the course organizer publishes course contents, organizes learning activities, and initiates discussion topics through the curriculum center platform. After the learners register, they log in to the curriculum center platform to participate in learning, and pass blogs, forums, and other social learning tools. Record study notes, share learning experiences, and conduct learning exchanges.

The course organizer organizes and screens the content generated by the learner in the interactive activities with the students such as learning and discussion, and feeds back to the learner via RSS or E-mail. According to the progress of the course, you can learn to give up last or halfway, but after completing the assignment and passing the test, you can obtain the e-learning certificate for the course [2]. 


\section{Advantages of the MOOC Teaching Model}

Although MOOC is derived from online distance education, it is more interactive. Compared with traditional college classroom teaching and online courses, the advantages of MOOC are mainly reflected in the following three aspects.

Although students are required to complete the course according to the prescribed schedule, there is no mandatory time and place for students to study courses and complete homework. Students can flexibly arrange learning time within the prescribed time limit. The location truly implements learning centered teaching. The course video is fragmented according to the knowledge of the lecture content. The average length of a video is 8-12 minutes, which is in accordance with the concentration rule of the human brain. It is also convenient to use the mobile terminal for fragmented learning.

The video course of MOOC sets up the interaction with the learner. Generally after completing the explanation of the knowledge points in the video unit of this section, the platform conducts the embedded quizzes in the form of objective questions. The learner only has to answer questions. Continue studying. On the other hand, the course forum on the MOOC platform provides communication between teachers and students. Teachers can set discussion topics. Students can discuss topics, share ideas, and initiate topics or ask questions on their own. Other learners can answer and there will be a dedicated course assistant to answer. Learners can also spontaneously use the more familiar platforms such as blog, Face-book, Wei-bo, and QQ Group to develop the second classroom and engage in more forms of interaction.

In addition to the embedded real-time tests in the course, the MOOC platform setup also includes the after-school test and peacetime job module. After the test, the objective questions are the main ones. After the learners answer the questions, they get feedback and explanations. Usually homework is generally open subjective topics. Course organizers have published detailed scoring standards. Learners upload their homework assignments for review by teachers or other learners. Some MOOC platforms even stipulate that each learner must review the specified number of other people's homework in order to effectively complete the assignment. The final exam is the last step for the learner to complete the course. The learner will only take the exam according to the requirements of the MOOC platform. After the exam is completed, the learner will receive the course study certificate. For the learning content generated during the course of the course, such as discussion topics, daily assignments submitted, and common questions raised by learners, the MOOC course organizer team will analyze, organize, and summarize the feedback to learners. At the same time and the feedback information can be used as a new round of MOOC curriculum resources [3].

To sum up, MOOC has fundamentally challenged the classroom teaching model that emphasized "granting" in the past. Teachers have more played the role of the initiator and organizer of the curriculum. Learners participate in curriculum learning through various social tools. They are no longer simple knowledge receivers, but have the role of curriculum builders, and they have a more open and more interactive learning environment. Compared with traditional online courses, MOOC curriculum resources are more abundant and learning interaction is enhanced, which is conducive to consolidating teaching quality.

\section{Construction of College Network Teaching Mode Based on MOOC}

The introduction of MOOC courses in college teaching adopts the online teaching model. The revolutionary significance of MOOC lies in its combination of online courses and local actual university teaching, and the two-way interaction between "online education" and "offline education".

Prepare online before class. In the context of informationization, teaching is no longer based on knowledge transfer from a single language symbol, but is based on multimodal, multi-channel information transfer and communication, and on the basis of multiple forms of knowledge understanding and construction. In the MOOC-based college teaching model, teachers are the 
facilitators of student learning. They manage online teaching content through the MOOC platform, design teaching activities, and help students build a reasonable knowledge structure and system. College students have a certain ability to judge is the real decisive factor in the quality of the curriculum, through the MOOC platform to self-preparation, take the initiative to identify problems and give full play to autonomy.

High-quality curriculum resources are the basis of learning. First of all, teachers should choose teaching courseware, teaching videos and other types of multimedia teaching resources according to teaching objectives, teaching content, and students' cognitive characteristics. Teaching videos can be made using high-quality MOOC teaching resources or recorded by instructors of the course themselves. Second, teachers divide teaching content into several modules or knowledge points according to the knowledge structure. Reasonable fragmented teaching resources are beneficial to the use of college students in the mobile age. Fragmentation time to learn, while training their information integration capabilities; Finally, students use the teaching resources provided by teachers, the problems and difficulties into the resource management system, teachers based on this teaching content design and teaching activity design. The teaching content design includes teaching plan, curriculum objectives and course content, setting targeted, diversified, stratified teaching objectives as well as teaching weights and difficulties; teaching activity design refers mainly to group discussion, division of learning tasks, and setting evaluation criteria.

Classroom assisted teaching. The network teaching model reconstructs the teaching flow, from the traditional "pre-teaching and learning" to "learning after education." Teachers use classroom teaching to help students achieve the absorption and internalization of knowledge points. Classroom is the best place for teachers and students to interact with each other. Teachers give the students the initiative to understand the students' learning situation through organizing class discussions, listening to learning reports, viewing work results, and conducting simple assessments.

MOOC's learning content is presented in a variety of ways and is attractive. In the teaching process, targeted MOOC video clips that support classroom teaching can effectively mobilize the vitality of classroom teaching. For the teaching difficulty, students discuss the problems around the class, through the communication with peers to find a solution to the problem, teachers participate in discussions when necessary, and timely feedback to inspire students thinking, based on the promotion of personalized learning guaranteed the quality of teaching [4].

As an extension of classroom learning, MOOC Discussion Forums provide online communication for teachers and students. There are three solutions to the problems encountered by students: First, students do not fully understand the content taught in the classroom and can watch the teaching videos again. Second, for the mistakes in the homework, please answer the correct students. Analyze and explain, students solve problems collaboratively; Students feedback to teachers the difficulties encountered in the learning process, teachers perform one-to-one or one-to-many guidance to achieve teaching goals. In addition, teachers can enrich their extracurricular activities and broaden their horizons of knowledge by sending course-related links. By posting in the discussion forum and organizing student exchanges and cooperation, students can participate in discussions without time and place, save time and cost, and improve learning efficiency.

According to different evaluation purposes, the evaluation is divided into formative evaluation and summative evaluation. The formative evaluation refers to the students' usual performance and periodical test scores. Among them, the usual performance includes pre-learning situation, class participation and after-school discussion. The summative assessment is a test of the student's learning situation in a semester, that is, the final exam results. The teacher can create a database of test questions, enter test data, and perform phase tests on students. The generated statistical report is part of the teacher's evaluation of students. At the same time, the students quantify the acquisition of each knowledge point in the statistical report. As a result, students' learning situation was mastered and the teaching progress was further adjusted. By creating a job library, evaluate students' submitted assignments and send comments to students in a targeted manner. In addition, teachers can also participate in metrics statistics by using MOOC background data tracking to count 
student's courseware browsing times, discussion forum visits, and so on.

According to different evaluation subjects, the evaluation is divided into self-evaluation and external evaluation. Self-evaluation refers to students' evaluation of their knowledge, learning outcomes, and peer communication skills. The external evaluation mainly comes from two aspects, namely peer evaluation and teacher evaluation. Students can find inadequacies, adjust learning methods, and improve learning efficiency based on the evaluation results. Teachers can sum up experiences based on the evaluation results, improve the teaching strategies for follow-up teaching activities, and stimulate students' potential [5].

MOOC is a product of the development of the information society. It can meet the individual needs of learners, promote the fairness of education, and share quality educational resources. It also brings opportunities and challenges for the reform of higher education. Colleges and universities are important institutions for disseminating knowledge and cultivating talents. It is necessary to embed MOOCs in teaching effectively so as to form a joint force for the development of higher education. The MOOC-based network teaching model constructed in this paper is based on the principle of easy operation, flexibility, and humanization. It provides an overall framework and reference model for the introduction of MOOCs in universities. On this basis, colleges and universities can further construct corresponding MOOC teaching models according to the characteristics of specific subjects and professions, in order to stimulate the vitality of classroom teaching and improve the quality of teaching.

\section{Conclusion}

At this stage of the society, not only people with rich knowledge but also people with comprehensive capabilities and qualities are required. Therefore, we need to choose a variety of channels and approaches for talent development. Teaching based on MOOC is a major attempt in the field of education in our country, and it is of great significance to students, teachers and even educators. Therefore, this issue should be thoroughly explored and studied so as to achieve better and higher teaching goals.

\section{Acknowledgements}

Fund Project: Research Project on the Construction of Teaching Quality Monitoring System Based on Big Data Mining and Analysis (2017YB130). Research Project of Higher Education Teaching Reform in Jilin Province Research on the Reform of the Talent Cultivation Model for Continuing Education (2105ZCY330)

\section{References}

[1] Shi Min. Flip classroom application research in college sports teaching [J]. Journal of Yulin Teachers College, 2015 (2) .58

[2] Yan Fujun, Li Licong. China's MOOC development strategy research [J]. Chinese Distance Education, 2014 (11).63

[3] Zhao Haixia, Xie Shuyu, Liu Yonggui, Huang Ya. The development path, strategic influence and rational thinking of higher education MOOC [J]. Modern Educational Technology, 2014 (7).85

[4] Yuan Li, Stephen Powell, Ma Hongliang, Wu Yonghe. The impact of MOOC on higher education: A theoretical perspective of disruptive innovation [J]. Modern Distance Education Research, 2014 (2).145

[5] Zhang Jianwei, Tang Weidong. The exploration and thinking of college sports teaching model based on MOOC [J]. Chinese school sports, 2016(1) .34

[6] Chen Jianwei. The current situation and development countermeasures of college sports online courses in China in the era of MOOC[J]. Journal of Chengdu Sport University, 2015 (3) .55 